\title{
Mal Orang Sehat Sebagai Penerapan Paradigma Sehat Dan Respon Masyarakat Berdasarkan Precaution Adoption Process Modkl Di Puskesmas Sobo, Kabupaten Banyuwangi
}

\author{
Khansa Fatihah Muhammad*¹, Ratna Dwi Wulandari ${ }^{1}$ \\ ${ }^{1}$ Departement of Health Administration and Policy, Faculty of Public Health, \\ Airlangga University, Indonesia
}

Author's Email Correspondence (*): khansa.fatihah.muhammad2016@fkm.unair.ac.id (+6287777398073)

\begin{abstract}
ABSTRAK
Kabupaten Banyuwangi pada awal tahun 2019 meresmikan program pelayanan 'Mal Orang Sehat (MOS)' dan diimplementasikan pada seluruh 45 Puskesmas di Banyuwangi. MOS bertujuan untuk mewujudkan paradigma sehat yang juga merupakan salah satu prinsip penyelenggaraan Puskesmas. Kunjungan masyarakat untuk mendapatkan pelayanan MOS disebut juga dengan, "Kunjungan sehat". Target capaian MOS adalah persentase kunjungan sehat yang lebih tinggi dari kunjungan sakit. Berdasarkan data dari Dinas Kabupaten Kesehatan Banyuwangi, diketahui bahwa pada bulan Januari sampai Desember 2019, persentase kunjungan sehat terendah di Kabupaten Banyuwangi berada di Puskesmas Sobo dengan persentase sebesar 7,47\%. Penelitian yang menggunakan metode deskriptif kuantitatif ini ini dilakukan untuk mengetahui respon masyarakat terhadap pelayanan MOS di Puskesmas berdasarkan Precaution Adoption Process Model (PAPM). Teknik sampling yang digunakan adalah proportional sampling dengan sejumlah 100 orang sampel yang merupakan masyarakat di wilayah kerja Puskesmas Sobo. Hasil penelitian menunjukkan bahwa mayoritas responden masyarakat (51\%) berada pada stage 1 berdasarkan PAPM, yang berarti mayoritas masyarakat wilayah kerja Puskesmas Sobo sama sekali belum mengetahui adanya pelayanan MOS di Puskesmas. Oleh karena itu, rekomendasi yang dapat diberikan adalah dengan meningkatkan dan memperkuat promosi kesehatan MOS, agar lebih banyak masyarakat yang mengetahui pelayanan MOS dan demi terwujudnya target capaian MOS di Puskesmas.
\end{abstract}

Kata Kunci: Mal Orang Sehat, Paradigma Sehat, Precaution Adoption Process Model

Published by:

Tadulako University

Address:

J1.Soekarno Hatta KM 9. Kota Palu, Sulawesi Tengah, Indonesia.

Phone: +628114120202

Email: Preventif.fkmuntad@gmail.com
Article history :

Received : 02022021

Received in revised form : 03022021

Accepted : 05022021

Available online 31122021 


\begin{abstract}
Banyuwangi District on the early 2019 has officially launched a program called 'Mal Orang Sehat (MOS) to be implemented in all 45 Primary Health Care in Banyuwangi. MOS has main purpose is to manifesting a health paradigm which also one of the Primary Health Care principles. People visitation to get the MOS service on the Primary Health Care that is called as health visit. MOS has a main goal,that is the health visit percentage have to be higher than a sick visit. Based on the data from Banyuwangi Health District, on the January until December 2019, the lowest health percentage compared to sick visit is in Sobo Primary Health Care with the percentage of 7,47\%. This research that has descriptive quantitative method used Precaution Adoption Process Model (PAPM) to determine the level of action for community behavior towards MOS services in Sobo Primary Health Care. The sampling technique for this research is proportional sampling with the sample of 100 people who are in the working area of Sobo Primary Health Care. Research result shows that the majority of people is on the stage 1 of PAPM (51\%), which means the majority of people don't know MOS services at all. Therefore, the recomendation that can be given to Puskesmas Sobo is to increase and strengthen the health promotion for MOS., and for the realization of MOS target achievement.
\end{abstract}

Keywords: Health Paradigm, , Health Visit, Mal Orang Sehat, Precaution Adoption Process Model

\title{
PENDAHULUAN
}

Paradigma sehat merupakan salah satu prinsip penyelenggaraan puskesmas (14), paradigma sehat merupakan salah satu pilar utama dalam Program Indonesia Sehat (6). Tren paradigma sehat ini membuat Puskesmas perlu memperkuat upaya promotif dan preventif (3). Oleh karena itu, Dinas Kesehatan Kabupaten Banyuwangi pada awal tahun 2019 telah meresmikan program Mal Orang Sehat (MOS). Program pelayanan Mal Orang Sehat (MOS) dilaksanakan pada seluruh 45 Puskesmas yang ada di Kabupaten Banyuwangi. MOS memiliki pengertian fasilitas pelayanan kesehatan di Puskesmas dan jaringannya yang memberikan layanan promotif dan preventif dengan sasaran masyarakat sehat (2). Pelayanan MOS memiliki 4 bidang layanan, yaitu pelayanan informasi, pemeriksaan untuk pemeliharaan dan peningkatan kesehatan, konseling, penjaringan dan penggerakan peran serta masyarakat, dimana pada masing-masing bidang layanan terdapat beberapa pelayanan (2). Pelayanan MOS pada satu Puskesmas dan lainnya diantara seluruh 45 Puskesmas di Kabupaten Banyuwangi dapat memiliki jenis pelayanan atau nama program dalam pelayanan yang berbeda, Contohnya adalah Puskesmas Sempu yang memiliki beberapa program inovasi pada pelayanan MOS, Puskesmas Songgon, dan Puskesmas lainnya di Kabupaten Banyuwangi. 
Berdasarkan hasil wawancara, diketahui bahwa kunjungan masyarakat yang berada dalam kondisi sehat untuk mendapatkan pelayanan MOS kemudian juga disebut sebagai 'kunjungan sehat'. Pencatatan untuk pelayanan MOS dilakukan secara elektronik melalui SIMPUSWANGI (Sistem Informasi Puskesmas Kabupaten Banyuwangi) dan manual melalui tertulis, pelaporan dilakukan rutin pada setiap bulan, triwulan, dan tahunan (2). Persentase kunjungan sehat dibandingkan dengan kunjungan sakit pada seluruh 45 puskesmas di Banyuwangi pada bulan Januari-Desember 2019 adalah sebesar 26,95\%..

Berdasarkan data keseluruhan 45 Puskesmas di Kabupaten Banyuwangi, diketahui bahwa puskesmas dengan persentase jumlah kunjungan sehat dibandingkan kunjungan sakit terendah adalah Puskesmas Sobo (7.47\%). Sementara itu, persentase kunjungan sehat dibandingkan kunjungan sakit tertinggi adalah Puskesmas Songgon (56.46\%). Keberhasilan kunjungan sehat dilihat dengan melakukan perbandingan persentase kunjungan sehat dan kunjungan sakit (2). Berdasarkan pernyataan dari Dinas Kesehatan Kabupaten Banyuwangi (2019), pelayanan MOS dinilai sudah mencapai target capaian apabila persentase kunjungan sehat lebih tinggi dibandingkan persentase kunjungan sakit.

Oleh karena itu, penelitian ini bertujuan untuk mengetahui hal yang dapat direkomendasikan untuk meningkatkan pelaksanaan Mal Orang Sehat khususnya di Puskesmas Sobo dengan mengetahui tingkat tindakan perilaku kesehatan atau precaution masyarakat di wilayah kerja Puskesmas Sobo terhadap adanya pelayanan Mal Orang Sehat di Puskesmas berdasarkan Precaution Adoption Process Model (PAPM).

\section{METODE}

Penelitian ini merupakan penelitian deskriptif kuantitatif. Penelitian dilakukan pada masyarakat di wilayah kerja Puskesmas Sobo yang meliputi. Waktu pengumpulan data dilakukan pada bulan Maret sampai dengan Mei tahun 2020. Data pendukung yang digunakan adalah data sekunder dari Dinas Kesehatan Kabupaten Banyuwangi mengenai persentase kunjungan sehat dan kunjungan sakit selama bulan Januari sampai dengan Desember 2019. Pengumpulan data penelitian dilakukan dengan pengisian kuesioner melalui google form yang dilengkapi dengan panduan tata cara pengisian kuesioner dan penjelasan sebelum penelitian. Pengambilan sampel dilakukan menggunakan teknik proportional sampling dengan perhitungan sebagai menggunakan rumus slovin sebagai berikut: 


$$
\mathrm{n}=\frac{\mathrm{N}}{\mathrm{N}(\mathrm{d})^{2}+1}
$$

Keterangan:

$\mathrm{n}=$ Jumlah sampel yang diperlukan

$\mathrm{N}=$ Jumlah populasi yang ada

$\mathrm{d}=$ Presisi

Sehingga, didapatkan perhitungan sampel sebagai berikut:

$$
\begin{aligned}
n= & \frac{46622}{46622(10 \%)^{2}+1}=99 \\
& =100 \text { jumlah sampel }
\end{aligned}
$$

Keterangan:

$\mathrm{N}=46622$ (Jumlah populasi masyarakat wilayah kerja Puskesmas Sobo)

$\mathrm{d}=10$

\section{HASIL}

Berdasarkan hasil penelitian, dapat diketahui bahwa persentase kunjungan sehat terendah dari keseluruhan 45 Puskesmas di Kabupaten Banyuwangi adalah Puskesmas Sobo yaitu sebesar 7.47\%. Kemudian, pada (Tabel 1) dibawah ini merupakan hasil penelitian yang menunjukkan bahwa mayoritas masyarakat di wilayah kerja Puskesmas Sobo berada pada stage 1 berdasarkan PAPM.

Tabel 1

Pengklasifikasian Responden Masyarakat Wilayah Kerja Puskesmas Sobo terhadap awareness mengenai Mal Orang Sehat berdasarkan Precaution Adoption Process Model

\begin{tabular}{ccc}
\hline Stage dalam PAPM & N & $\%$ \\
\hline Stage 1 & 51 & $51 \%$ \\
Stage 2 & 17 & $17 \%$ \\
Stage 3 & 3 & $3 \%$ \\
Stage 4 & 0 & $0 \%$ \\
Stage 5 & 11 & $11 \%$ \\
Stage 6 & 1 & $1 \%$ \\
Stage 7 & 17 & $17 \%$ \\
\hline
\end{tabular}

Sumber: Data Primer (2020) 
Stage 1 dalam PAPM memiliki penjelasan dimana seseorang sama sekali belum mengetahui adanya awareness dan pengetahuan terkait sebuah tindakan perilaku (1), dalam hal ini yaitu pengetahuan terkait pelayanan MOS, karena seseorang tersebut belum pernah mendapatkan informasi terkait MOS dari Puskesmas, atau sumber informasi lainnya seperti keluarga atau orang terdekat. Stage 2 adalah dimana seseorang telah mengetahui adanya hal terkait kesehatan (10), dalam hal ini yaitu pelayanan MOS, tetapi belum melakukan tindakan apapun dan belum membuat keputusan terhadap kunjungan sehat melalui pelayanan MOS.Stage 3 adalah dimana seseorang belum memiliki keputusan akhir terhadap tindakan perilaku (4), dalam hal ini yaitu untuk melakukan kunjungan sehat atau tidak. Seseorang dalam stage 3 masih memiliki beberapa pertimbangan untuk melakukan tindakan perilaku (11), dalam hal ini yaitu dalam melakukan kunjungan sehat, seperti pertimbangan terkait jenis pelayanan MOS yang sekiranya akan dikunjungi, atau pertimbangan terhadap hal yang dapat menghalangi seseorang untuk melakukan kunjungan sehat. Sementara itu, stage 4 adalah tahapan dimana seseorang memutuskan untuk tidak melakukan tindakan apapun terhadap awareness yang dimiliki terkait sebuah tindakan perilaku (5), dalam hal ini yaitu untuk melakukan kunjungan sehat. Hal ini dapat dipengaruhi beberapa hal, salah satunya seperti masyarakat yang merasa belum membutuhkan melakukan kunjungan sehat, adanya halangan dari segi akses ke Puskesmas, atau hal lainnya. Stage 5 merupakan tahapan dimana seseorang telah memiliki keputusan untuk melakukan kunjungan sehat, tetapi baru memiliki rencana terhadap jenis pelayanan MOS yang akan dikunjungi, dan belum melakukan kunjungan sehat tersebut. Pada stage 6, seseorang sudah melakukan kunjungan sehat, tetapi tidak berencana untuk kembali melakuan kunjungan sehat dalam 6 bulan kedepan. Pada stage 7, seseorang sudah melakukan kunjungan sehat dan berencana untuk kembali melakukan kunjungan sehat dalam 6 bulan kedepan, setelah terakhir kali seseorang tersebut melakukan kunjungan sehat (9)

\section{PEMBAHASAN}

Program MOS merupakan program yang berfokus pada promotif dan preventif kesehatan untuk meningkatkan derajat kesehatan masyarakat dan merupakan kelompok sasaran besar dengan tingkat partisipasi rendah, seperti yang dapat diketahui dari hasil penelitian bahwa mayoritas responden masyarakat dengan persentase 51\% di wilayah kerja Puskesmas Sobo sama sekali belum mengetahui adanya pelayanan MOS di Puskesmas. Salah satu tujuan utama dari 
penyelenggaraaan program MOS menurut pernyataan PJ Program MOS di Puskesmas Sobo adalah agar masyarakat dapat melakukan deteksi dini terhadap penyakit (2). Menurut Peraturan Menteri Kesehatan Republik Indonesia Nomor 74 Tahun 2015, deteksi dini dilakukan untuk menemukan faktor risiko dan penyakit sedini mungkin pada individu dan/atau kelompok masyarakat secara rutin melalui wawancara, pengukuran, dan pemeriksaan. Kemudian pada pasal 19, dijelaskan bahwa deteksi dini merupakan salah satu kegiatan dalam upaya pencegahan penyakit yang penyakit perlu didukung dengan promosi kesehatan dan surveilans kesehatan (13).

Berdasarkan (Tabel 1), dapat diketahui bahwa mayoritas responden masyarakat di wilayah kerja Puskesmas Sobo berada di stage 1 berdasarkan PAPM (51\%). Stage 1 adalah dimana seseorang sama sekali tidak memiliki pengetahuan mengenai adanya pelayanan MOS di Puskesmas, sehingga mayoritas masyarakat belum memiliki pemikiran atau pertimbangan untuk melakukan kunjungan sehat melalui pelayanan MOS di Puskesmas.

Dinas Kesehatan Kabupaten Banyuwangi (2020) menyebutkan bahwa target capaian untuk pelayanan Mal Orang Sehat adalah persentase kunjungan sehat yang lebih tinggi dibandingkan kunjungan sakit. Peningkatan awareness terhadap pentingnya melakukan kunjungan sehat melalui program MOS di Puskesmas dapat didukung dengan melakukan promosi kesehatan. Tujuan promosi kesehatan menurut WHO adalah untuk mengubah perilaku individu atau masyarakat di bidang kesehatan (15). Pada pelaksanaan promosi kesehatan, terdapat dua jenis strategi yang dapat diperkuat, yaitu strategi dari segi metode dan media promosi kesehatan, serta sumber daya yang memadai (8). Kemudian, berdasarkan hasil penelitian, dapat diketahui bahwa persentase kunjungan sehat terendah pada bulan Januari-Desember tahun 2019 adalah di Puskesmas Sobo dengan persentase sebesar 7.47\%. Sementara itu, persentase kunjungan sehat tertinggi pada Januari-Desember tahun 2019 terdapat di Puskesmas Sempu dengan persentase sebesar $53.26 \%$.

Oleh karena itu, rekomendasi yang dapat diberikan meningkatkan awareness dan pengetahuan masyarakat terhadap pentingnya melakukan kunjungan sehat melalui program MOS adalah perbaikan dan peningkatan sarana dan prasarana yang dapat mengacu pada Peraturan Menteri Kesehatan Nomor 31 Tahun 2018 ,(12) pada pelayanan MOS, pelatihan khusus untuk petugas MOS, serta sosialisasi MOS yang dilakukan secara lebih terencana dan terjadwal, agar tercapainya perwujudan paradigma sehat dan peningkatan kunjungan sehat, khususnya di Puskesmas Sobo, Kabupaten Banyuwangi. 


\section{KESIMPULAN DAN SARAN}

Berdasarkan hasil penelitian, dapat diketahui bahwa mayoritas responden masyarakat di wilayah kerja Puskesmas Sobo dengan persentase sebesar 51\% berada pada stage 1 berdasarkan PAPM. Stage 1 dalam hal ini bermakna bahwa mayoritas responden masyarakat sama sekali belum mengetahui adanya pelayanan MOS di Puskesmas. Saran yang dapat diberikan kepada Puskesmas Sobo untuk pelaksanaan Mal Orang Sehat adalah denganpeningkatan sarana dan prasarana pelayanan MOS, pelatihan petugas MOS, juga meningkatkan promosi kesehatan seperti melalui sosialisasi (secara internal dan eksternal) (7), dan memperkuat promosi kesehatan melalui gerakan pemberdayaan, advokasi, bina suasana dan kemitraan untuk dapat meningkatkan perwujudan paradigma sehat dan meningkatkan derajat kesehatan masyarakat melalui kunjungan sehat dan untuk pengetahuan masyarakat terhadap pelayanan MOS di Puskesmas.

\section{DAFTAR PUSTAKA}

1. Chapin, J. Adolescents and Cyber Bullying: The Precaution Adoption Process Model. Educ Inf Techol; 2016; Vol 21:719-728.

2. Dinkes Banyuwangi. Kesehatan Kabupaten Banyuwangi. Petunjuk Pelaksanaan Mal Orang Sehat. 2018. Dinas Kesehatan Banyuwangi. 2018.

3. Direktorat Kesehatan dan Gizi Masyarakat, Kedeputian Pembangunan Manusia, Masyarakat dan Kebudayaan, Kementerian PPN/Bappenas. Buku Penguatan Pelayanan Kesehatan Dasar Di Puskesmas. Jakarta Pusat. 2018.

4. Haas EJ. Applying the Precaution Adoption Process Model to the Acceptance of Mine Safety and Health Technologies. Occupational Health Science. Occupational Health Science; 2018; Vol.3 No.1:43-66.

5. Hassan, H., King, M., Watt, K., Examination of the precaution adoption process model in understanding older drivers' behaviour: An explanatory study. Transportation Research Part F: Traffic Psychology and Behaviour; 2017; Vol 46; 111-123.

6. Kemenkes RI. Rencana Aksi Kegiatan Pusat Analisis Determinan Kesehatan 2016-2019'. Pusat Analisis Determinan Kesehatan. Sekretariat Jenderal. 2016. Kementerian Kesehatan Republik Indonesia. 2016.

7. Kemenkes RI. Petunjuk Teknis Penguatan Manajemen Puskesmas dengan Pendekatan Keluarga. 2016. Kementerian Kesehatan Republik Indonesia. 2016.

8. Keputusan Menteri Kesehatan Republik Indonesia Nomor 585 Tahun 2007 Tentang Pedoman Pelaksanaan Promosi Kesehatan di Puskesmas. 
9. Konig M Laura, Gudrun Sproesser,Harald T Schupp,Britta Renner. Describing the Process of Adopting Nutrition and Fitness Behavior Stage Model Approach. JMIR MHealth and Unhealth. University of Konstanz Germany. 2018.Vol.6 No.1.

10. Mahmoodabad S.S.M.,Morad A.Z.,Mohsen A.,Alireza B. Prevention Determinants of Falling in the Elderly Citizens: a Precaution Adoption Process Model (PAPM) Carried-out in Urmia, Iran. Ambient Science. National Care Research and Protection Organization. India; 2018;

11. Mahmoodabad SS, Asadian A, Fallahzadeh H., Rajei M. A questionnaire on factors affecting the precaution adoption process model for cervical cancer - Psychometric Properties. J Edu Health Promot 2020; Vol 9:278.

12. Permenkes RI. Peraturan Menteri Kesehatan Nomor 31 Tahun 2018 Tentang Aplikasi Sarana, Prasarana, dan Alat Kesehatan. Permenkes RI; 2014.

13. Permenkes RI. Peraturan Menteri Kesehatan Republik Indonesia Nomor 74 Tahun 2015 Tentang Upaya Peningkatan dan Pencegahan Penyakit. Permenkes RI;2015.

14. Permenkes RI. Peraturan Menteri Kesehatan Nomor 75 Tahun 2019 Tentang Pusat Kesehatan Masyarakat. Permenkes RI; 2019.

15. Tedi,Fadli, Ridho R. Hubungan Program Germas terhadap Kebiasaan Hidup Masyarakat yang Telah dan Belum Mendapatkan Sosialisasi di Wilayah Kerja Puskesmas Kecamatan Suakrame Palembang. JPP (Jurnal Kesehatan Palembang). 2018; Vol.13 No.1. 